\title{
How Second (L2) and Heritage (HL) Language Learners Can Draw on Existing Knowledge to Overcome Common Discourse Issues in Spanish Compositions
}

\author{
John M. Ryan \\ University of Northern Colorado, USA \\ Víctor Parra-Guinaldo \\ Prince Mohammad Bin Fahd University, Saudi Arabia
}

\begin{abstract}
Student error analysis is an area of investigation that can shed light on how students learn. It can also serve as a pedagogical tool to increase students' awareness of the most common types of errors to avoid. Quality of student output, however, isn't solely determined by the number of errors students make, but also the extent to which students successfully employ certain other discourse-related strategies to improve their compositions. This paper argues that, aside from grammatical concerns, and at least from a discourse point of view, students already possess much of the knowledge they need in order to write better compositions. Both second (L2) and heritage (HL) learners of Spanish typically already possess some advanced writing skills in English, but we have observed that when attempting to write in Spanish, many of these same students will resort to more remedial means of presenting and/or expressing their ideas. In other words, unaware that so many discourse skills are transferable from English to Spanish, students will not necessarily apply the same strategies, or at least to the same degree, as they would if writing a similar essay in English. This paper, therefore, provides ten tips that students can draw on to improve both the presentation and expression of their ideas in compositions. Recommendations are divided into two categories, the first being aspects a student should always keep in mind when approaching any piece of writing, while the second are negative tendencies that are quite common, but which a student should necessarily avoid.
\end{abstract}

Index Terms - composition studies, discourse skills, Spanish, heritage language (HL) learners, second language (L2) learners

\section{INTRODUCTION}

Throughout the past ten years that the first author of this paper has taught Spanish composition at the University of Northern Colorado, he has noticed certain common patterns of errors among his students. Some of these he was already quite familiar with from his own experience as a second language learner of Spanish, but others only became more apparent to him as an instructor. About five years ago, he began noticing a steady growth in the number of heritage (HL) language learners enrolling in what were previously his almost exclusively non-heritage (L2) Spanish classrooms. This situation prompted him to undertake a pilot study to collect, analyze and compare a total of thirty grammatical and discourse level errors from a mixed class of fifteen HL and L2 students. The study would produce two articles (Ryan 2018 and 2019), the first of which, in addition to providing a much-needed quantitative comparative error analysis, offered recommendations for how instructors like himself could address these errors with both groups of students. The second article introduced a new self-evaluation/peer evaluation module that could be utilized in composition classes for combined groups.

As both Ryan (2018) and (2019) demonstrate, student error analysis is indeed an area of investigation that not only helps shed light on how students learn, but it also serves as a pedagogical tool that can be used to increase students' awareness of the most common types of errors to avoid. Nevertheless, the more time the authors of this paper have spent reviewing student compositions, the more we have come to realize that the quality of student output is not determined solely by the number of grammatical errors students make, for yet an equally important factor that helps make a good composition is the extent to which students draw on other skills that have more to do with overall presentation and expression of ideas. For example, we have noticed that some students, despite making abundant wordor sentence-level errors, still demonstrate such skills as planning, organizing, and brainstorming, all of which contribute in their own ways to better essays. 
This article marks the third in a sequence of papers on the topic of HL and L2 Spanish compositions. Whereas the first two papers of the series focused more on things that both students and instructors can do to improve grammatical errors at word- or sentence-level, the purpose of this third paper is to shift the focus from the notion that writing can be improved based on the eradication of quantifiable errors to the idea that there are other, more abstract issues in student writing at the level of discourse. Such factors as style, structure, cohesion and coherence cannot necessarily be quantified, and students may indeed improve on these things by employing the same strategies they already use when they write in English. The recommendations of this paper are divided into two categories, the first being those aspects that a student can and should always keep in mind when approaching any piece of writing, such as creativity, word choice, connectors, transitions, verb tense and sentence length. The second category of recommendations consists of three tendencies observed in student writing that should be avoided at all costs, namely, repetition and redundancy, stream of conscious writing, or the sense of an unfinished essay. ${ }^{1}$

\section{Previous Work: ERrors, Mistakes ANd Pitfalls (ESCOLLOS)}

As pointed out in Ryan (2018), a significant amount of work has appeared in the literature on the writing of L2 compositions and error analysis, for Spanish or otherwise, as demonstrated by Nas \& Van Esch (2014); Van Beuningen (2010); Schoonen et al. (2009), Carduner (2008); Truscott (2007); Ferris (2004); DeHaan \& Van Esch (2005); Roca de Larios et al. (2002); Silva (1993); Valdés et al. (1992) and Schneider \& Connor (1990). and (2019). Additionally, as further pointed out in Ryan (2019), the effectiveness or utility of teacher and peer feedback has also been examined by Hyland \& Hyland (2006), Cotterall and Cohen (2003), Brinkman (2003), Liu and Hansen (2002), and Chaudron (1984).

More pertinent to this paper is work by those scholars who have suggested there to be differences between "errors" and "mistakes." According to Brown (2006) and others (Corder 1967; Ellis 1994), errors are inaccuracies produced by a speaker due to the lack of knowledge of an appropriate vocabulary item, a grammatical point or some convention. Mistakes, on the other hand, are failures in production in which vocabulary, grammar or conventions are indeed known, but for one reason or another are produced inaccurately, not because of the lack of knowledge, but more like momentary omissions or gaffes due to other, competing communicative needs of the moment. Brown goes on to say that even L1 speakers commit mistakes for similar reasons such as tiredness, slips of the tongue, or the short-term inadequacy of memory load in processing lengthier utterances.

Table 1 demonstrates the quantification of word-level composition errors found for HLs from Ryan (2018):

TABLE 1:

\begin{tabular}{|c|c|c|c|c|c|c|c|c|c|c|c|c|c|}
\hline \multicolumn{14}{|c|}{ FREQUENCY DISTRIBUTION OF HL WORD-LEVEL ERRORS FOR ALL COMPOSITIONS (Ryan 2018) } \\
\hline & \multirow{2}{*}{\multicolumn{2}{|c|}{$\begin{array}{l}\text { (1) } \\
\text { C-1 }\end{array}$}} & \multirow{2}{*}{\multicolumn{2}{|c|}{$\begin{array}{l}(2) \\
\text { C-2 }\end{array}$}} & \multirow{2}{*}{\multicolumn{2}{|c|}{$\begin{array}{l}\text { (3) } \\
\text { C-3 }\end{array}$}} & \multirow{2}{*}{\multicolumn{2}{|c|}{$\begin{array}{l}\text { (4) } \\
\text { C-4 }\end{array}$}} & \multirow{2}{*}{\multicolumn{2}{|c|}{$\begin{array}{l}\text { (5) } \\
\text { C-5 }\end{array}$}} & \multirow{2}{*}{\multicolumn{2}{|c|}{$\begin{array}{c}(6) \\
\text { Totals } \\
\end{array}$}} & \\
\hline & & & & & & & & & & & & & \\
\hline & \# & $\underline{\%}$ & \# & $\underline{\%}$ & \# & $\underline{\%}$ & \# & $\underline{\%}$ & \# & $\underline{\%}$ & \# & $\underline{\%}$ & \\
\hline accent & $1 \overline{7}$ & $56.67 \%$ & $4^{-}$ & $30 . \overline{77} \%$ & $\overline{24}$ & $54.55 \%$ & $\overline{19}$ & $47 . \overline{50} \%$ & $\overline{10}$ & $32.26 \%$ & $\overline{74}$ & $46.84 \%$ & \\
\hline spelling & 7 & $23.33 \%$ & 2 & $15.38 \%$ & 9 & $20.45 \%$ & 4 & $10.00 \%$ & 9 & $29.03 \%$ & 31 & $19.62 \%$ & \\
\hline wrong word & 0 & $0.00 \%$ & 2 & $15.38 \%$ & 5 & $11.36 \%$ & 4 & $10.00 \%$ & 4 & $12.90 \%$ & 15 & $9.49 \%$ & $.18 \%$ \\
\hline capitalization & 1 & $3.33 \%$ & 3 & $23.08 \%$ & 3 & $6.82 \%$ & 4 & $10.00 \%$ & 2 & $6.45 \%$ & 13 & $8.23 \%$ & \\
\hline number & 1 & $3.33 \%$ & 0 & $0.00 \%$ & 0 & $0.00 \%$ & 3 & $7.50 \%$ & 2 & $6.45 \%$ & 6 & $3.80 \%$ & \\
\hline $\operatorname{mood}$ & 2 & $6.67 \%$ & 0 & $0.00 \%$ & 0 & $0.00 \%$ & 1 & $2.50 \%$ & 2 & $6.45 \%$ & 5 & $3.16 \%$ & \\
\hline verb form & 1 & $3.33 \%$ & 0 & $0.00 \%$ & 2 & $4.55 \%$ & 2 & $5.00 \%$ & 0 & $0.00 \%$ & 5 & $3.16 \%$ & \\
\hline tense & 1 & $3.33 \%$ & 1 & $7.69 \%$ & 0 & $0.00 \%$ & 1 & $2.50 \%$ & 0 & $0.00 \%$ & 3 & $1.90 \%$ & \\
\hline dir. obj. pron. & 0 & $0.00 \%$ & 0 & $0.00 \%$ & 1 & $2.27 \%$ & 1 & $2.50 \%$ & 0 & $0.00 \%$ & 2 & $1.27 \%$ & \\
\hline prep. pron. & 0 & $0.00 \%$ & 1 & $7.69 \%$ & 0 & $0.00 \%$ & 1 & $2.50 \%$ & 0 & $0.00 \%$ & 2 & $1.27 \%$ & $.82 \%$ \\
\hline gender & 0 & $0.00 \%$ & 0 & $0.00 \%$ & 0 & $0.00 \%$ & 0 & $0.00 \%$ & 1 & $3.23 \%$ & 1 & $0.63 \%$ & \\
\hline ind. obj. pron & 0 & $0.00 \%$ & 0 & $0.00 \%$ & 0 & $0.00 \%$ & 0 & $0.00 \%$ & 1 & $3.23 \%$ & 1 & $0.63 \%$ & \\
\hline adverb & 0 & $0.00 \%$ & 0 & $0.00 \%$ & 0 & $0.00 \%$ & 0 & $0.00 \%$ & 0 & $0.00 \%$ & 0 & $0.00 \%$ & \\
\hline copula & $\underline{0}$ & $\underline{0.00 \%}$ & $\underline{0}$ & $\underline{0.00 \%}$ & $\underline{0}$ & $0.00 \%$ & $\underline{0}$ & $0.00 \%$ & $\underline{0}$ & $0.00 \%$ & $\underline{0}$ & $0.00 \%$ & \\
\hline totals & 30 & $100.00 \%$ & 13 & $100.00 \%$ & 44 & $100.00 \%$ & 40 & $100.00 \%$ & 31 & $100.00 \%$ & 158 & $100.00 \%$ & \\
\hline
\end{tabular}

As Ryan (2018) points out, according to the data in Table 1, a full $84.18 \%$ of all word-level errors committed by HL participants in that study are represented by errors in the first four categories, from highest to lowest as indicated in column (6), namely: 1) incorrect (or missing) accent mark ( $\mathrm{n}=74 ; 46.84 \%) ; 2$ ) incorrect spelling $(\mathrm{n}=31 ; 19.62 \%) ; 3$ ) use of the wrong word $(n=15 ; 9.49 \%)$; and 4$)$ incorrect capitalization $(n=13 ; 8.23 \%)$. Because such errors can be identified and quantified, an instructor can indicate by means of a code every time a particular error appears on a

\footnotetext{
${ }^{1}$ The publication of this article was supported by the University of Northern Colorado Fund for Faculty Publications and a portion of the research with a 2017 UNC Summer Support Initiative Award No. QS232.

${ }^{2}$ For additional context regarding the studies cited here, we refer the reader to the following sections, "I. Previous Composition Error Studies" in Ryan (2018) and "III. Prior Research" in Ryan (2019).
} 
student's composition, and depending on the number of times that code appears, the student can determine how much of a deficit the corresponding grammar point represents. ${ }^{3}$

In contrast to errors or mistakes, yet another concept is that of "pitfall," or escollo in Spanish. A pitfall can be described as some obstacle or hurdle that is typically encountered, but not immediately obvious to the speaker or writer. In other words, pitfalls are potential problems, and if you are aware of what they are ahead of time, you can overcome them. What makes a pitfall different from an error or a mistake is that it is, by its very nature, something that can be avoided before it happens. Unlike errors or mistakes, pitfalls are not as easily quantifiable. ${ }^{4}$

One example of a typical pitfall in student writing is repeated use of a given term or expression, and although its appearance is grammatically correct each time, its continued presence is excessive to the point of becoming distracting to the flow of the composition. Since the repeated word or expression is used correctly each time, it is not necessarily an error so to speak; however, from the point of view of style, any sensible person reading the essay would assert that it would be advisable to explore alternate ways of expressing the concept expressed by the original term. Another example of an item that is not as easily quantified is in the suggestion that a student composition include transitions between sentences or paragraphs where none existed.

\section{Discussion: TiPs FOR DEALING With Discourse Pitfalls of SPANish COMPOSITIONS}

As indicated previously, what distinguishes this paper from the previous two of the series is the shift in focus from that of dealing with errors committed to one that has to do with bypassing potential issues. In other words, instead of an arguably negative orientation which looks back with an eye to correct, this paper instead takes the more positive stance by looking ahead with a focus on best practices. The idea is to make students aware of strategies and tools they already possess to make them more aware and active writers. In fact, the method we use to help students improve their compositions at the level of discourse is based on the premise that students already possess much of the knowledge they need to write better compositions. Both L2 and HL students typically already have advanced writing skills in English but it is curious that when these same students attempt to write in Spanish, a strange sort of mental block sets in and it's almost as if they've erased from memory some of the very things they typically do when confronted with a writing exercise in English. What many students don't understand is that so many discourse skills are transferable from English to Spanish.

The following ten tips are based on those discourse issues or pitfalls that appear to be common among student compositions.

\section{What to do:}

\section{Reread the first draft}

At the beginning of every semester, just after they've received comments on the first draft of their first composition, the authors typically hold individual meetings with students to discuss their recently completed essay. The agenda for this meeting is simple, to start the process of getting the student to think more critically of their writing even before they begin to make corrections. The very first item of business at this meeting is for the student to reread their composition to themselves from beginning to end, and as they do so for them to ask themselves whether they would write a similar composition in the same way in English. Almost every time without fail, after reading their work, the student will lift their head with perhaps a smile, an expression of awe, or even a shake of their head in astonishment, and answer in the negative. We conduct this exercise precisely because having students reread their composition this way forces them to directly compare their discourse strategies in both languages, and by doing so, it draws their attention to skills and strategies they typically use for English that they could have used just as well for the paper at hand.

For this exercise to be successful, it is critical that an instructor specify to students that this read-through of their composition is not at all a word-for-word translation to English, but more simply, a reflection about how they would have written it in English. Rather, its purpose is to evoke for the student the overall "feel" of their composition. Reading through their initial draft in this way helps students realize the gap between what they mean to write and what they actually wrote, and to challenge them to venture beyond their comfort zone. At times, students simply settle for more familiar words and structures because those are the ones on which they may have come to rely, either because they have been successful using them in the past, or because they can be retrieved on the fly or in a rush when needed.

Furthermore, the authors agree that this exercise can be seen as the first necessary step in encouraging students to take risks with their writing, by getting them to work harder to express what they actually mean with more precise vocabulary or more complex constructions. We have found that once a student knows that it is not just acceptable to take risks, but even more importantly, advisable to do so, it is much easier for them to be receptive to exploring the additional remaining tips below that can further improve their essays from a discourse perspective.

\section{Envision the overall structure and presentation of an essay before you start writing}

\footnotetext{
${ }^{3}$ Only word-level error results for HLs are presented here for purposes of illustration. For a more complete analysis, see Ryan (2018) for results pertaining to HL sentence-level errors and both word- and sentence-level errors for L2s.

${ }^{4}$ The Spanish word escollo, whose literal translation into English is 'reef,' 'sandbank,' or the Indo-European Anglo Saxon reflex 'shoal', is also used in a figurative sense to mean 'pitfall' or 'obstacle.' It is interesting that both languages draw upon a similar semantic concept of 'potential entrapment' or 'tripping over something,' as in the English concept of 'falling into a pit' or that of Spanish, of 'tripping over rocks or the coral of a reef.'
} 
One of the most common pitfalls to which students typically fall prey as they begin to write is a lack of forethought or planning about how their essay will unfold. The few moments a student takes before putting pen to paper can be beneficial, because at this point the mind has not yet become cluttered with specific grammar or vocabulary concerns. In other words, the student can still see the big picture of their composition, because they haven't yet begun to deal with the gory details.

Once they've thought about the structure their overall composition should take, the very next item a student should consider is how to begin their work. An opening sentence, or paragraph for longer compositions, not only gives initial structure to a student's work, but it can also provide direction to the reader in that it makes clear where the remainder of the paragraph or longer essay is headed. Also, because introductory statements tend to be unique to the writer, these or other devices can at the same time make your composition more appealing as well as innovative. Alternatives to opening statements or paragraphs might be the use of a poignant or controversial quotation, or some question the student is trying to answer by the end of the essay. For example, if a student sits down to write a personal narrative, fiction, or a dialog between two people, s/he might start with some statement made by a person central to the plot. This can set both the mood and tone for the remainder of the composition.

Another consideration a student can make at this initial juncture with regard to overall presentation of their essay is whether it is worth experimenting with perspective or point of view. For example, if the student is writing something that is normally written in the third person, such as a descriptive essay, s/he might try writing it in the first person as if it were happening to them; conversely, if they are drafting a personal narrative that reads more like a diary entry, they might try writing it instead in third person as if they were simply an observer.

\section{Vary sentence length}

In addition to an adequate introduction, another important structural aspect to any essay written in a target language is the proper management of sentence length. Some students think that if they keep their sentences short, they will generate fewer errors. While this can be true, however, the strategy to keep sentences shorter, can unfortunately have some additional negative side-effects from the point of view of discourse. For example, an essay written exclusively with shorter sentences typically sounds simplistic, creates a rhythm that is repetitive and even monotone. Students who continue to employ the same simple sentence structure of S(ubject)-V(erb)-O(bject), without adding some level of complexity throughout their compositions, run the risk of making their essay sound dull and uninteresting, even when the topic itself may be interesting or even compelling.

Consider the following sequence of Spanish sentences (1)(a) from an actual student essay, and its English equivalent in $(1)(b)$ :

(1)(a) Nuestros profesores entienden la situación. No hay dinero para el programa. Deben buscar alternativas.

(1)(b) 'Our professors understand the situation. There is no money for the program. They must seek alternatives.'

Although all three sentences in (1)(a) are perfectly well-formed, repetition of simple S-V-O structure in all three cases produces a simplistic and monotonous tone with a more or less repetitive rhythm. Interestingly, the first sentence, though short itself, has the potential to make an impact, but seems to get lost in the monotony of the entire sequence of similarly structured sentences. Now consider, however, the revised sentence in (2)(a), and its English equivalent in (2)(b):

(2)(a) Nuestros profesores entienden la situación. No hay fondos para mantener el programa y por lo tanto van a tener que buscar alternativas.

(2)(b) 'Our professors understand the situation. There are no funds to maintain the program and therefore, they will have to look for alternatives.'

As (2)(a) suggests, by combining the last two sentences the first sentence, which in fact has not changed at all from its original state, acquires more impact because, at least from a discourse perspective, it has now acquired a more contrastive quality when juxtaposed with the now larger subsequent sentence. This small versus larger arrangement makes the text stand out not just structurally, but it also has the additional effect of giving the message of the statement a more punctuating quality than it had before.

The misguided strategy of keeping sentences short is neither realistic nor practical, because when we write we typically write in more, rather than less, complex ways than that in which we speak. What is recommended instead, as we have shown with example, (2)(a), is that we vary sentence length between short and long sentences to create a more dynamic, rather than the monotonous rhythm as suggested by (1)(a). When students become more adept at creating longer sentences, an occasional short sentence can actually become more effective as a means of punctuating the essay.

Another negative side-effect of frequent or exclusively short sentences is that it is often necessary to repeat words throughout a paragraph that would not be required if conjunctions or relative pronouns were used to connect separate clauses. Tip 4 below speaks more to this strategy.

\section{Use "meaningful" conjunctions and relative clauses to expand sentences}

The preceding tip spoke to the monotonous and simplifying effects that repeated short sentences can have on an essay. One of the ways to address the problem of short sentence length is to connect separate clauses with meaningful conjunctions and relative pronouns. Students typically start out by overusing more simple conjunctions, such as pero 'but' or porque 'because,' both of which convey basic semantic relationships. Although incorporating these into sentences can be a proper first step in addressing the tendency pointed out in the previous paragraph, namely, that which 
students have for writing short sentences, such basic conjunctions are limited in what they contribute to the overall meaning of the sentence.

Certain, more "meaningful" conjunctions as sin que 'without which,' con tal (de) que 'provided that,' a menos que 'unless,' or a pesar de que 'in spite of,' etc., are so much more substantive semantically in the sense that they can convey more nuanced relationships between clauses than the more simple porque or pero could ever hope to achieve. In fact, these more powerful conjunctions can help strengthen sentences by making a student's arguments that much stronger, as well as help make points more persuasive. Such conjunctions can be especially challenging for HL students at first since they are usually not part of the conversational repertoire these students are used to, but with practice they can expand and supplement a student's writing resources.

Relative clauses are another way of creating more interesting and complex structure and students can be encouraged to employ these as well. Each group has its own challenges in the use of relative pronouns correctly, L2s typically resorting to overuse of quien at the expense of que (which can be used for both people and things, while some HLs are unaware of the more complex uses of relative clauses.

Consider the following sequence of actual Spanish sentences produced by a student in (3)(a), and their English equivalents in (3)(b):

(3)(a) Ese hombre me hace reir. Él es más gracioso que cualquier otro hombre que he conocido.

(3)(b) 'That man makes me laugh. He is funnier than any other man I have met.'

Although the sentences in (3)(a) are perfectly well-formed, they include redundant information in three places (as indicated by the bolded, underlined words). A student can be shown to economize and avoid such redundancy by: 1) combining the two sentences by means of a relative construction; and 2) converting the adjective otro 'other' into a pronoun, whereby the second use of hombre can be deleted. These simple changes can make the resulting sentence more coherent, as in (4)(a), with its English equivalent (4)(b):

(4)(a) Ese hombre, que es más gracioso que cualquier otro que he conocido, me hace reir.

(4)(b) 'That man, who is funnier than any other I've met, makes me laugh.'

Another way students can combine shorter sentences is with the use of meaningful subordinative conjunctions/expressions. Consider the following sequence of actual Spanish sentences produced by a student in (5)(a), and their English equivalents in (5)(b):

(5)(a) Irán al partido mañana. Solamente si no llueve.

(5)(b) 'They'll go to the game tomorrow. Only if it doesn't rain.'

Once again, although the sentences in (5)(a) are perfectly formed grammatically, the way in which they appear together conveys a rather simplistic and rhythmically monotonous tone. A way to avoid this is to combine the sentences with a meaningful conjunction or subordinating expression that implies the same condition established by the if-clause of the second sentence expressed by Solamente si..., 'Only if...' Any such subordinating conjunctions or expressions as a menos que or a no ser que, both meaning 'unless,' or con tal de que no 'provided that it not...,' etc., would be appropriate in this case as illustrated in (6)(a), and its English translation in (6)(b).

(6)(a) Irán al partido mañana a no ser que llueva.

(6)(b) They'll go to the game tomorrow unless it rains.'

An additional factor that must be considered when presenting this tip for both groups is that, with increased use of subordinating conjunctions and relative pronouns, some structures, though not necessarily all, are more susceptible to trigger the subjunctive mood. This presents students with yet an additional challenge, especially for those students who are still struggling with the distinction between the two moods, or the sequence of tenses, so instructors may want to coordinate making this recommendation at the same time they are teaching those grammatical points.

As subordinate and relative clauses imply more complex constructions, they are naturally more frequent in written than in oral form, and therefore are most appropriate in preparing students to write more complex discourse.

\section{Use transitions between sentences for greater coherence}

Somewhat related to the previous tip that helps connect separate clauses within sentences, this tip instead has more to do with the connection of sentences within paragraphs. Students can use transitions and connectors to help make their paragraphs flow both internally and between each other. They can be shown how this makes their essays easier to read and it also helps organize their thoughts and tighten their composition, all of which keeps the reader on track and focused.

Students should consider using such expressions as primero 'first,' luego 'then,' después 'later', or por último 'finally,' when organizing individual events in a narrative, or other expressions such as a diferencia de 'unlike,' en cambio 'instead,' por una/otra parte 'on the one/other hand,' or por consiguiente or por lo tanto, both meaning 'therefore,' when constructing a comparative essay. There are many such expressions to choose from to convey different assertions the writer would want to convey with the additional benefit of helping move their composition along from one sentence to the next.

6. Consider verb tense

Although on the surface it may seem something purely grammatical, the tense of a verb can actually be quite powerful in communicating the precise timing between two actions, as regards the perfect tenses (formed with haber 
'have' + past participle); it can also be used in a discursive way in order to create a certain mood or tone of the sentence or paragraph.

Bleichman \& Cañón (2011) illustrate in (7)(a), which is translated in (7)(b) how Colombian author García Márquez (1991) in a section from his short story, La siesta del martes, utilizes all three past tenses, the past perfect, preterit and imperfect, to convey the different timing and aspects of a past situation he represents in the story:

(7)(a) A las doce había empezado el calor. El tren se detuvo diez minutos en una estación sin pueblo para abastecerse de agua. Afuera, en el misterioso silencio de las plantaciones, la sombra tenía un aspecto limpio."

(7)(b) 'By twelve the heat had begun. The train stopped for ten minutes at an unnamed station to get water. Outside, in the eerie silence of the plantations, the shade had a clean look.' [our translation]

Consider the differences between the three tenses utilized in (7)(a) basic aspectual differences between preterit and imperfect tenses that can be used in the traditional manner to relate different perspectives of a past action. Students should be given ample opportunity to practice utilizing the different past (including perfect) tenses so that they have a clear understanding on how these should be used to correctly employ the traditional uses of these tenses.

On the other hand, the tense of a verb can also sometimes be used more to create a certain mood or tone. Consider the use of the imperfect by some authors to create a sense of immediacy or in the moment sensation in the narration of a situation. Reyes (1990) underscores this fact that the imperfect tense, in addition to its more traditionally known aspectual usage, has also a lesser-known discourse application. Consider the following authentic examples (8)(a), (9)(a) and (10)(a) from Reyes (1990), and their corresponding English equivalents (our translation) in (8)(b), (9)(b) and (10)(b), all of which outline different discourse uses of the imperfect tense.

(8)(a) Al amanecer salió el regimiento, atravesó la montaña, y poco después establecía contacto con el enemigo

(8)(b) 'The regiment left at dawn, crossed the mountain, and shortly thereafter established contact with the enemy.'

(9)(a) Ayer moría Borges en Ginebra.

(9)(b) Yesterday Borges died in Geneva.

(10)(a) Escuchábamos la sinfonía número 28 de Mozart.

(10)(b) We were listening to Mozart's Symphony No. 28.

For all three examples, Reyes explains that the imperfect is used to achieve more intimate involvement by the reader in the action being expressed. In (8)(a), which is an example she draws from the Esbozo of the RAE (1914), ${ }^{5}$ Reyes points out that the use of the imperfect establecía 'established' at the end of a series of several other verbs that are otherwise conjugated in the preterit tense signals a point in a succession of events at which comparable greater involvement is solicited of the reader in the action specified, suggesting that up until that point, the reader held a more passive role. In the case of (9)(a), a quote that she reportedly heard on a television news program, Reyes suggests that stylistic use of the imperfect moría 'died' served to highlight the act of dying as something that impacted the entire day, as opposed to being just one of several singular events that took place at a given moment. Reyes suggests that these two first examples may have their origin in literary usage that she points out also appearing in the Quijote.

However, it is Reyes's final example of Escuchábamos in (10)(a), which unlike both (8)(a) and (9)(a) is coincidentally a plausible utterance in English as well, hence the translation, 'We were listening to...' This last example is perhaps the least distant in terms of relevance to the reader. It is the epitome of an expression of involvement and perhaps the best example of how the imperfect can be employed to "involve" the reader/listener.

The moral of this section is that students should be encouraged to experiment with tense, just as they might with point of view, particularly with the imperfect, when they want to convey a more intimate relationship with the reader of their essay.

\section{Consider word choice}

The words chosen for a composition can have a great impact on the resulting product, and these should be considered from a variety of perspectives. To start with, students should always check their composition throughout for appropriate word choice in terms of redundancy. Repeated use of the same vocabulary or expressions can make an essay sound monotonous and uninteresting. Both HL and L2 learners may suffer from limited exposure to vocabulary, for different reasons; HL students because their vocabulary of everyday conversation or transfer from English, L2 students because they are limited to the word list from a chapter unit. In fact, one activity that HL and L2 students can do together is a prewriting step by brainstorming about and looking for synonyms or expressions that they can use to enhance their writing before they even put word to paper.

Ryan (2019) provides the example of a composition about dogs which has the potential of becoming rather boring if the word 'dog' is used excessively throughout; however, adding such colorful alternate words or expressions, like "man's best friend," or "little hairy companion," both of which have near equivalents in Spanish can significantly improve an essay, and in this case can even make it more endearing to the reader. Or perhaps you are writing about something that is burning in a house fire for which the notion of 'fire' might be expressed with las llamas "flames" or infierno "hell." The truth is that this same convention, which students are already familiar with in English, also exists for Spanish and can be applied to create more variety in word choice for an essay. What is required is a little imagination and ingenuity on the part of the student to take their writing to this additional step further.

\footnotetext{
${ }^{5}$ Esbozo de una gramática de la lengua española. (1914).

${ }^{6}$ Salvador Fernández: Ramírez. (1986). El verbo y la oración. In Bosque, Ignacio. Gramática española. Madrid: Arco Libros.
} 
Another factor affecting word choice is appropriateness. Some words are considerably more colloquial and should only be used in such contexts, such as the case of the use of nomás 'only' by HL speakers. One would never find this word used in more formal writing, such as a business letter. Some examples of inappropriate word choice for L2 learners would be the use of tú or '(informal) you' versus usted '(formal) you,' the inaccurate targeting of the copulas ser, estar, or haber, all three which mean 'to be' in different circumstances, or the incorrect selection of por and para, both prepositions meaning 'for,' but used differently for different purposes.

What NOT to do:

The last three recommendations of this paper are recommendations of what NOT to do when writing an essay. 8 . Avoid redundancy of structures

Whereas Tip no. 7 regarded the repetition of such individual lexical items as nouns, verbs, and adjectives and provided suggestions for how students might overcome limited vocabulary, the present recommendation, though also related to word choice, has more to do with redundancy that is less the result of word selection, but more implicit in other operations such as syntax. For example, some L2 learners who are at the beginning stages of writing tend to overuse of subject pronouns. It is widely known that unlike English, subject pronouns in most cases are not required in Spanish, unless they are used for emphasis or clarification.

\section{Avoid stream of consciousness (unless appropriate)}

Some writers string thoughts together with little or no punctuation, making text difficult to read. This happens with some HL learners who are beginner writers of Spanish who just simply string together their thoughts on a topic without separating them out with punctuation or some of the other strategies mentioned earlier, such as sentence or paragraph transitions or conjunctions. This last sentence is a good example of this type of writing.

Stream of consciousness, a type of writing where loose, unrelated and/or unstructured words or expressions are strung together to convey a disjointed stream of thought can be quite effective when writing personal narratives; particularly when the writer wants to convey confusion or to achieve a certain psychological effect, such as representing what random thoughts may be going through the mind of person in a particularly difficult situation. The result is a kind of organic type of writing that pays less attention to punctuation, structure, cohesion or coherence. Of course, this type of writing is not practical for all assignments, particularly those that are more formal in nature. However, students should be made aware of the possibilities and that additional resource. Most times, however, punctuation and clarity are necessary for the reader to understand what you write, the latter being permissible only in the unlikely case that a very specific type of writing assignment requires it, and for that reason alone may seem appropriate, and even effective.

\section{Avoid an incomplete essay}

Just as it is important to start off a composition with a compelling introduction of some sort, it is equally important to finish your composition in a way that doesn't just drop off without some kind of conclusion or statement that ties your entire work together. This can be in the form of concluding statement or paragraph, or even a question or quote that can be effective in driving home your thesis statement. If you began your essay with a question, the concluding paragraph or statement can come in the form of the answer to that question.

Just as the student was asked to reread their essay at the beginning of the journey to gain the sense or feel of an overall essay, the same student should also be asked to consider how the ending of their essay makes them feel, what sense does it give them. Do they feel that there is something missing? Does it just leave them hanging or, worse yet, like they've been pushed off a cliff without allowing them to say a few last words or, more simply, a goodbye.

In summary, Figure 1 illustrates all ten composition pitfalls suggested in this paper:

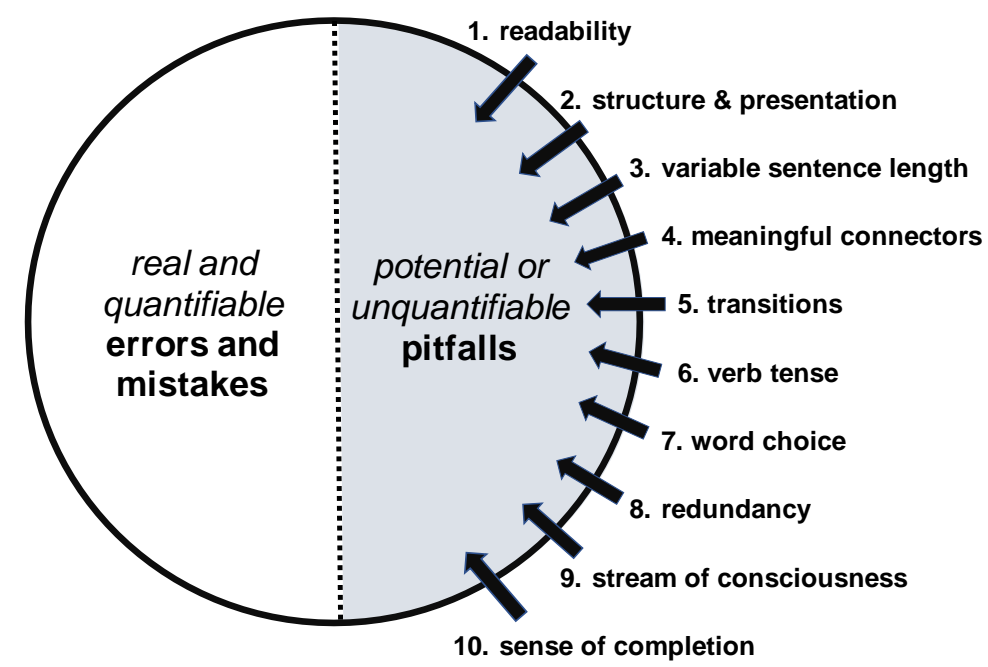

Figure 1. Contrast between quantifiable errors and mistakes and unquantifiable writing pitfalls

Figure 1 contrasts real, quantifiable errors and mistakes that students typically make in their compositions with the ten more unquantifiable pitfalls that students can potentially make. Since errors and mistakes are real and quantifiable, 
they are represented on the one hand by the clear, leftmost hemisphere of the circle. In contrast, as pointed out in the paper, pitfalls are less quantifiable because of their more abstract or subjective nature, and for that reason, they are demonstrated by the shaded region of the rightmost half of the circle. As this paper suggests, language instructors can guide students to consider these things more proactively when writing papers in the target language.

\section{CONCLUSIONS}

The goal of this paper was to contrast the more grammatical, hence quantifiable, word- and sentence-level composition errors that students make and the more discourse-oriented, paragraph-level pitfalls that these same students can overcome by following the ten recommendations for improvement, also made in this paper. While it is difficult to quantify the absence of effective qualities or strategies students could have employed when writing a paper, it is undeniable that the presence of these same items can significantly improve the overall flow, cohesion and conciseness of an essay, making it not only more readable, but more interesting as well. Many of the recommendations that have been suggested in this paper are indeed strategies that both L2 and HL students may already employ in their writing of English compositions but fail to do so in their writing of Spanish. One of the reasons for this difference may be that these students were outwardly trained and possess experience writing in English, whereas they lack the same training and experience writing in Spanish. I suggest that this may lead to a sort of beginning writer's block in Spanish, in which students temporarily forget some of the more common-sense strategies they customarily apply when they write in English. In other words, students should extend these best practices in terms of what they already know about English to Spanish as well. It is therefore recommended that students be trained to use these tips as they continue to evaluate their essays in Spanish until they feel more comfortable applying those skills they already possess for English.

\section{REFERENCES}

[1] Bleichman, G. \& P. Cañón. (2011). Taller de escritores. Menasha, WI: Vista Higher Learning.

[2] Brinkman, A. (2003). La eficacia del feedback de alumnos sobre los textos argumentativos de sus compañeros. Master's thesis. Nijmegen: Radboud University.

[3] Brown, H. D. (2006). Cross linguistic influence and learner language. In Principles of language learning and teaching (5th edn.). White Plains, NY: Addison Wesley Longman, Inc. pp. 248-81.

[4] Carduner, J. (2008). Teaching proofreading skills as a means of reducing composition errors. Language Learning Journal 35 : 2283-2295.

[5] Chaudron, C. (1984). The effects of feedback on students' composition revisions. RELC Journal, 15(2): 1-15.

[6] Corder, P. (1967). The significance of learner's errors. International Review of Applied Linguistics, 5: 161-170.

[7] Cotterall, S. \& R. Cohen (2003). Scaffolding for second language writers: Producing an academic essay. ELT Journal, 15(2): 158-166.

[8] DeHaan, P. \& K. van Esch. (2005). The development of writing in English and Spanish as foreign languages. Assessing Writing 10: 100-116.

[9] Ellis, R. (1994). The study of second language acquisition. Oxford: Oxford University Press.

[10] Ferris, D. R. (2004). The grammar correction debate in L2 writing: Where are we, and where do we go from here? (and what do we do in the meantime?). Journal of Second Language Writing, 13(1): 49-62.

[11] García Márquez, G. (1962). La siesta del martes. Norma S A Editorial.

[12] Hyland, K. \& F. Hyland. (2006). Feedback on second language students writing. Language Teaching, 39: 83-101.

[13] Liu, J. \& J. G. Hansen. (2002). Peer response in second language writing classrooms. Ann Arbor, MI: University of Michigan Press.

[14] Nas, M. \& K. van Esch (2014). Acquisition of writing in second language Spanish. In Geeslin, K., Ed. The handbook of Spanish second language acquisition. MA: Wiley Blackwell.

[15] Real Academia Española. (1914). Esbozo de una gramática de la lengua española, Madrid, Espasa-Calpe, pág. 461.

[16] Reyes, G. (1990). Valores estilísticos del imperfecto. Revista de Filología Española LXX: 45-70.

[17] Roca de Larios, J., L. Murphy \& J. Marín. (2002). A critical examination of L2 writing process research.” In Randsdell, S. \& M. Barbier (eds.), New directions for research in L2 writing. Dordrecht: Kluwer Academic Publishers.

[18] Ryan, J. M. (2019). "A comprehensive, research-based, peer review and self-evaluation module for integration into combined classes for second (L2) and heritage (HL) language learners of Spanish.” Journal of Language Teaching and Research 10 (6): 1131-1141.

[19] Ryan, J. M. (2018). "Spanish composition errors from a combined classroom of heritage (L1) and non-heritage (L2) learners: A comparative case study." Journal of Language Teaching and Research 9 (3): 439-452.

[20] Schneider, M. \& U. Connor. (1990). Analyzing topical structure in ESL essays: Not all topics are equal. Studies in Second Language Acquisition 12: 411-427.

[21] Schoonen R., P. Snellings, M. Stevenson \& A. van Gelderen. (2009). Toward a blueprint of the foreign language writer: The linguistic and cognitive demands of foreign language writing. In Manchón, R. (ed.), Writing in foreign language contexts: Learning, teaching and research. Bristol: Multilingual Matters.

[22] Silva, T. (1993). Toward an understanding of the distinct nature of L2 writing: The ESL research and its implication. TESOL Quarterly 27: 657-677.

[23] Truscott, J. (2007). The effect of error correction on learners' ability to write accurately. Journal of Second Language Writing 16 (4): $255-272$. 
[24] Valdés, G., P. Haro \& M. Echevarriarza. (1992). The development of writing abilities in a foreign language: Contributions towards a general theory of L2 writing. The Modern Language Journal 76: 333-352.

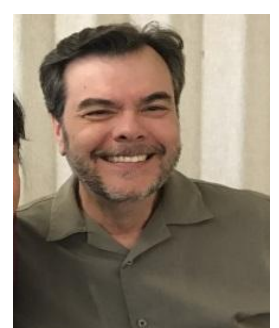

John M. Ryan earned his Ph.D. in Rhetoric, Composition, and Linguistics at Arizona State University in Tempe, Arizona, USA in 2008. He earned his master's degree in Spanish linguistics, also from Arizona State, in 1991. He earned his Bachelor of Science degree in Spanish from Georgetown University's School of Languages and Linguistics in Washington, D.C. in 1985.

$\mathrm{He}$ is currently Associate Professor of Spanish Linguistics at the University of Northern Colorado. His research on the acquisition of verbs by children and adults has been published in such journals as the Journal of Child Language and Development, Teaching and Practice in Language Studies and Hispania, and his first book, The genesis of argument structure: Observations from a child's early speech production in Spanish (Germany: Lambert, 2012), traces the emergence of the verb phase in the developing language of a monolingual child learning Peninsular Spanish. Other interests include historical news discourse of the Italian American community and the reconstruction of proto Ibero Romance, for which he has recently authored several scholarly papers for different edited volumes and is working on his second book.

Dr. Ryan is a member of the Linguist List International Linguistics Community, the Societas Linguistica Europaea, the Linguistic Society of America, the Rocky Mountain Modern Language Association, the Linguistic Association of the Southwest, the National Italian American Foundation, and the Italian American Historical Society.

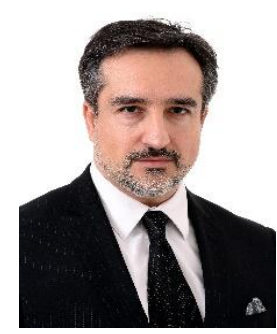

Víctor Parra-Guinaldo obtained both his master's and Ph.D. in Rhetoric-Composition, Linguistics and Applied Linguistics at Arizona State University and has since taught a variety of composition and linguistics courses at the undergraduate level and the MATESOL program.

His research agenda lies in two main areas: historical linguistics, and in particular morpho-syntactic phenomena within the Germanic and Romance language families, and applied linguistics, including secondlanguage teaching and learning and pedagogical practices. He has published his latest research with Routledge and Springer, among others, whereas his first publication was a book of poetry at the age of 23. Currently, he is collaborating with Alessandro Benati, a leading scholar in second language acquisition on Key Terms for Language Teachers. A Pocket Guide, soon to be published by Equinox Publishing.

Dr. Parra-Guinaldo is a member of the Linguist List International Linguistics Community, Linguistics Society of America (LSA), and Society for Germanic Linguistics. 